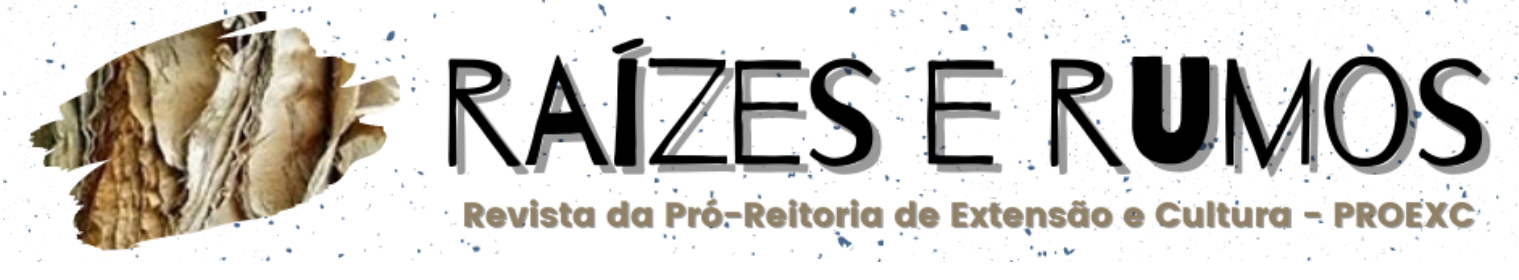

- ISSN: $2317-7705$ online ISSN: 0104-7035 impressc

\title{
Projeto Rádio Zói d'Água: memória, música e poesia dos Vales do Jequitinhonha e Mucuri
}

Projeto Rádio Zói d'Água: memory, music and poetry of the Jequitinhonha and Mucuri Valleys

José Carlos Freire ${ }^{1}$ Nathália Petrocelio Fonseca ${ }^{2}$ Herena Reis Barcelos ${ }^{3}$ Gheidlla Jheynnata Mendes Nogueira ${ }^{4}$ Rafael Lucas Santos Avelino ${ }^{5}$

\section{Resumo}

Em função do reconhecimento da importância da cultura para a formação do ser humano e sendo as manifestações culturais parte fundamental da identidade dos Vales do Jequitinhonha e Mucuri, o presente trabalho analisa o processo de desenvolvimento de três ações do Projeto de Extensão Rádio Zói d'Água, da Universidade Federal dos Vales do Jequitinhonha e Mucuri, compreendendo-o como um instrumento de valorização e divulgação das produções artísticas e culturais das regiões onde se insere a Universidade, sobretudo a produção musical e literária. O projeto permitiu o experimentar da interdisciplinaridade, o aprimoramento da competência linguística oral e escrita, bem como a oportunidade de reflexão por parte daquele que produziu o conteúdo informado, estimulando ainda o trabalho em equipe. Os três programas desenvolvidos, a saber, "Prosa de Domingo", "Prosa de Cultura" e "Prosa Literária", permitiram que a Universidade potencializasse sua interação e integração social.

Palavras-chave: Arte. Cultura. Regionalidade. Interdisciplinaridade.

\begin{abstract}
Considering the role of culture in the processes of human development and identity formation in the Jequitinhonha and Mucuri Valleys, this paper analyzes the implementation of three initiatives under the university extension project "Rádio Zói

\footnotetext{
${ }^{1}$ Docente do Departamento de Ciências Humanas e Sociais da Universidade Federal dos Vales do Jequitinhonha e Mucuri (UFVJM) - freire.jose@hotmail.com

2 Discente no curso de Serviço Social da Universidade Federal dos Vales do Jequitinhonha e Mucuri (UFVJM) - nathalia.petrocelio@ufvjm.edu.br

${ }^{3}$ Discente no Programa de Pós-Graduação em Estudos Rurais da da Universidade Federal dos Vales do Jequitinhonha e Mucuri (UFVJM) - herena.barcelos@ufvjm.edu.br

${ }^{4}$ Educadora popular e coordenadora da Rede de Cursinhos Populares Podemos+ gheidlla15@yahoo.com.br

5 Escritor e atuante em instituições de educação e negócios para microempreendedores rafaelande@gmail.com
} 


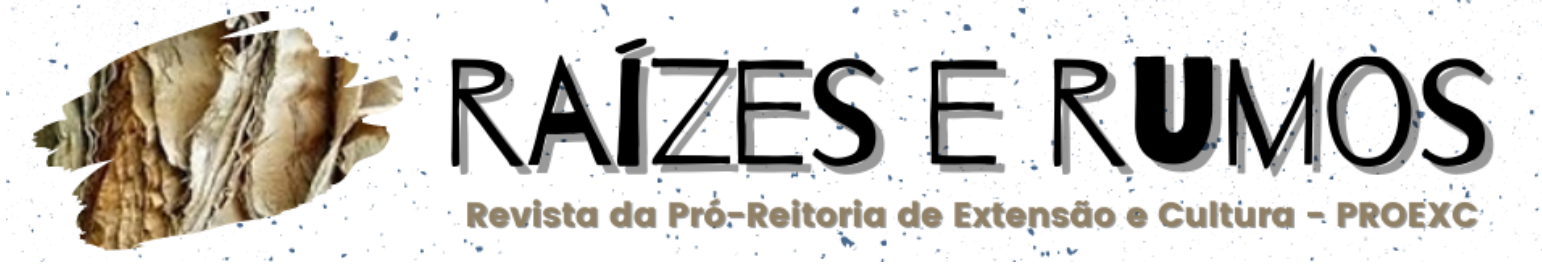

ISSN: $2317-7705$ online ISSN: 0104-7035 impressc

d'Água," from the Federal University of the Jequitinhonha and Mucuri Valleys. It argues that the project has been instrumental in the valorization and dissemination of artistic and cultural productions, especially in their musical and literary dimensions, in the regions where the University is located. The project allowed an experimental approach to the development of oral and written linguistic competence. It also enabled an opportunity for collective reflection among the producers and research team on the interdisciplinary nature and scope of the aired programs. The three programs developed under this extension project - "Prosa de Domingo", "Prosa de Cultura" and "Prosa Literária" -, enabled the University to enhance its insertion and integration within the broad society where its is located.

Keywords: Art. Culture. Religiosity. Interdisciplinarity.

\section{Introdução}

"Pra que nossa memória não se acabe em poeira": a célebre frase da canção Trem da História, do menestrel Rubinho do Vale, é ideal para representar o Projeto de Extensão "Rádio Zói d'Água". A extensão universitária oportuniza experiências únicas de troca de saberes entre o meio acadêmico e a comunidade. A Universidade pública tem entre suas tantas funções a de formar cidadãos conhecedores e engajados no espaço social em que estão inseridos e a cultura é um importante caminho de reconhecimento e pertencimento social.

A Universidade Federal dos Vales do Jequitinhonha e Mucuri (UFVJM), em particular, tem como missão: "Produzir e disseminar o conhecimento e a inovação, integrando o ensino, a pesquisa e a extensão como propulsores do desenvolvimento regional e nacional" (UFVJM, s/d). Tal propósito está em sintonia com o artigo 207 da Constituição Federal que traduz a importância da extensão como um dos pilares do ensino superior: "As universidades gozam, na forma da lei, de autonomia didáticocientífica, administrativa e de gestão financeira e patrimonial e obedecerão ao princípio da indissociabilidade entre ensino, pesquisa e extensão" (BRASIL, 1988).

O agora "Projeto Rádio Zói d’Água: memória, música e poesia dos Vales" é uma atividade de extensão vinculada à Pró-Reitoria de Extensão e Cultura (PROEXC) da UFVJM, iniciado em janeiro de 2021. Seu histórico tem relação com uma iniciativa 
passando a ter como elemento central a divulgação de artistas dos Vales do Mucuri e do Jequitinhonha. A sonoridade da viola e a musicalidade caipira continuaram presentes, porém não como ponto principal.

A interação com o público ouvinte por meio de recados e mensagens também foi um aspecto que se manteve. De janeiro a julho de 2021 foram 27 episódios, com duração entre 25 e 30 minutos. Durante esse período a estrutura básica do programa ficou assim organizada:

- Boas-vindas;

- 1a parte: uma música diferente de compositores ou intérpretes da região de estilos diversos;

- 2a parte: destaque mensal para um artista ou trabalho cultural no campo da música;

- 3a parte: quadro "Hora de Poesia", com a apresentação de escritores(as) dos Vales e leitura de seus poemas;

- 4a parte: quadro "Momento caipira", com músicas que resgatam a memória dos antigos programas de rádio;

- Despedida.

A capa foi elaborada de maneira simples, com a foto "Beira do Jequitinhonha", de Rodrigo Barbosa, como pode ser visto na Figura 1. 


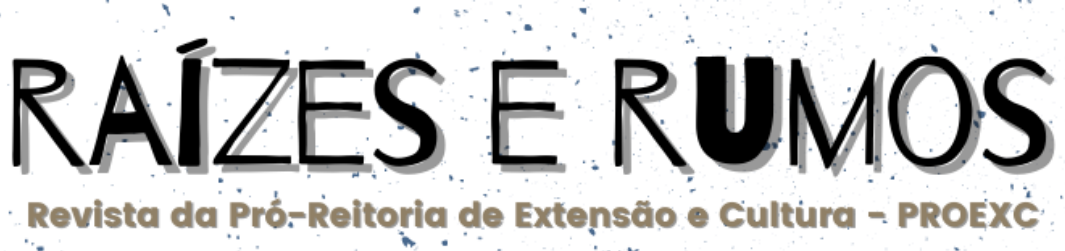

Figura 1: Capa do Programa “Prosa de Domingo” - edição de 16/05/2021

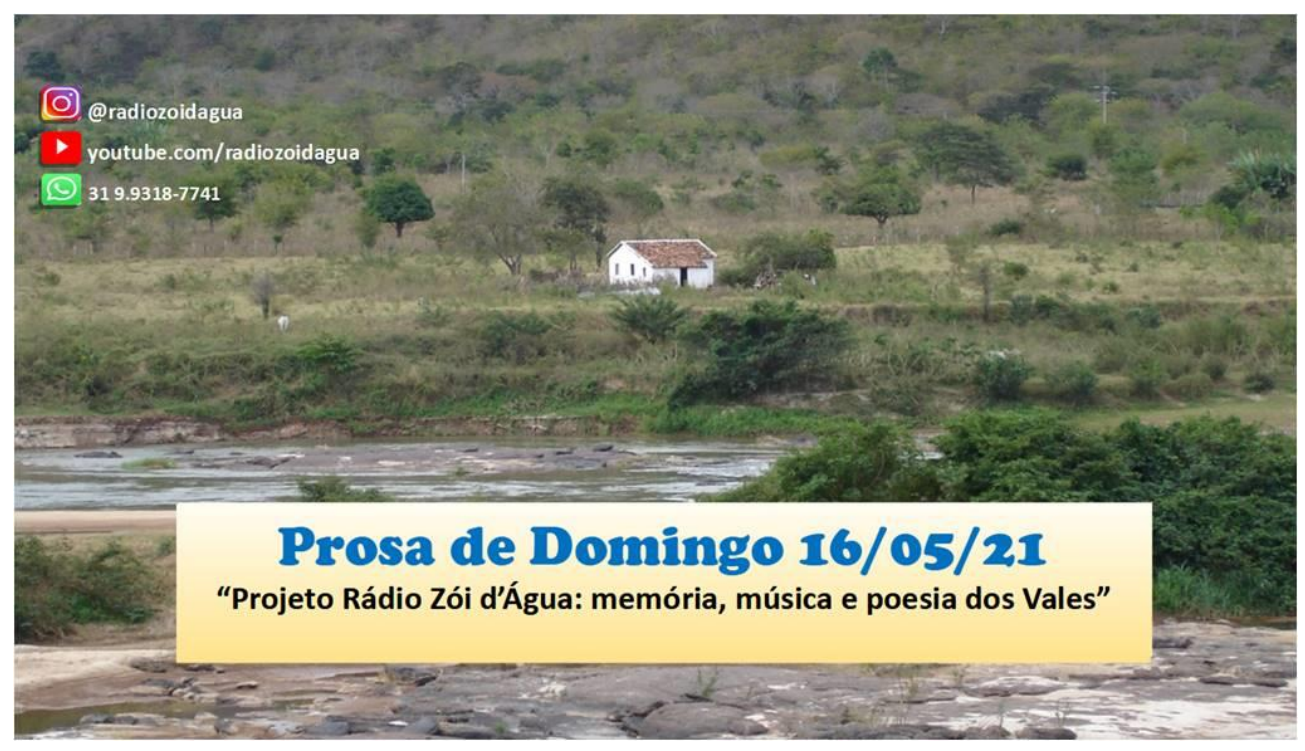

Fonte: Elaborada pela Equipe do Projeto. Foto de Rodrigo Barbosa (2021).

Na primeira parte já foram divulgados trabalhos musicais de: Bilora, Wilson Dias, Cícero Gonçalves, Pereira do Vale, Gustavo Guimarães, Joaci Ornelas, Chico Lobo, Dea Trancoso, Doroty Marques e Titane. Na programação especial do mês de junho, passaram pelo programa nomes como Flávio José, Lamartine Babo, Luiz Gonzaga e Ceumar. Na segunda parte, que destaca a cada mês um(a) artista ou trabalho cultural, foram apresentados: Beatriz Farias (janeiro), Carlos Farias e o Coral das Lavadeiras (fevereiro), Dea Trancoso (março), Tau Brasil (abril), Rubinho do Vale (maio), Trovadores do Vale (junho).

Já o quadro "Hora de Poesia" apresentou: Caio Duarte, Herena Barcelos, Marina Cangussu, Cris Sabino, Gonzaga Medeiros, Rafael Avelino, Sabiá Coitelinho, Vanessa Juliana, Maguidá Botelho, Cláudio Bento, Alex Konrado, Sândrio Cândido, Giselda Gil, Trabion, Iza Rodrigues, Mari Carvalho, Lívia Ferreira, Vinícius Figueiredo, Hérica Silva e Ísis Caldeira. Em edições especiais como o Dia do Trabalho e Dia da Mulher, foram lidos poemas de Eduardo Galeano e Conceição Evaristo. A quarta parte, constituída do "Momento caipira", procurou apresentar clássicos e releituras de músicas caipiras.

A recepção pelo público ouvinte foi muito boa durante esse período. Esse 


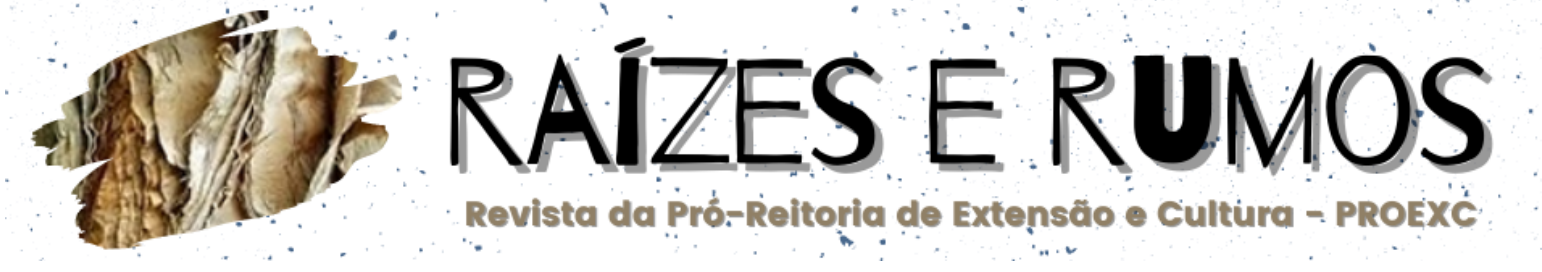

ISSN: $2317-7705$ online

vasto quadro artístico de poetas, compositores e intérpretes, articulando aspectos regionais e universais, possibilitou que pessoas de gostos musicais e poéticos diversos se interessassem pelo programa. Tomando como referência o canal do YouTube, notase que o número de visualizações do programa varia de 111 a 180 por semana. Os programas mais antigos, como os de janeiro e fevereiro, alcançam até 255 visualizações.

Outro indicativo são os comentários no canal. A cada semana há uma frequência de 12 a 15 comentários, de ouvintes antigos e novos. Além disso, nota-se que o número de inscritos praticamente dobrou, saltando de 261 em janeiro para 519 no final de julho.

Com base nesse percurso, a quarta temporada do "Prosa de Domingo" (agosto a dezembro de 2021) deverá manter a estrutura básica do programa, com alguns ajustes. Um dos elementos apontados na avaliação da equipe executora é a necessidade de divulgação de artistas musicais de estilos variados na primeira parte do atual formato. Avalia-se que o conjunto de artistas teve como marca preponderante o traço regionalista ou a sonoridade da viola. Embora a musicalidade regional permaneça como destaque, há uma gama de distintos estilos de artistas do Jequitinhonha e Mucuri, que pode valorizar ainda mais o programa.

Do seu lado, a viola deverá manter sua importância na programação, por meio do quadro "Música de Viola", no qual serão divulgados violeiros regionais consagrados e outros menos conhecidos. Já os quadros "Hora de Poesia” e "Momento Caipira" deverão ser mantidos. Espera-se que a próxima temporada dê continuidade ao trabalho de alegrar as manhãs de domingo dos(as) ouvintes, divulgando músicas, poesias e trabalhos de artistas dos Vales e de todo Brasil.

\section{Prosa de Cultura}

$\mathrm{O}$ "Prosa de Cultura" se configura como um programa de bate-papo com artistas, produtores e produtoras culturais, pesquisadores e pesquisadoras que tenham uma relação com os Vales do Jequitinhonha e do Mucuri. O programa tem 
semelhanças com o modelo de podcast, com duração média de uma hora e meia, conservando, porém, a característica da conversa livre com os(as) convidados(as).

Iniciado no mês de março de 2021, o programa teve seis edições, com intervalo de três semanas entre um e outro. A estrutura segue uma organização em três blocos: no primeiro, a pessoa convidada fala sobre sua trajetória, influências, formação artística etc.; no segundo bloco, há uma discussão sobre arte, cultura popular e os principais desafios da produção artística em âmbito nacional e local; o terceiro bloco apresenta os projetos em andamento por parte da pessoa convidada e perspectivas de trabalho e produção. A cada bloco, a pessoa convidada indica uma música ou poesia. A capa foi criada pela equipe, com imagem da obra de Gildásio Jardim.

Figura 2: Capa do Programa "Prosa de Cultura" - edição de 17/03/2021.

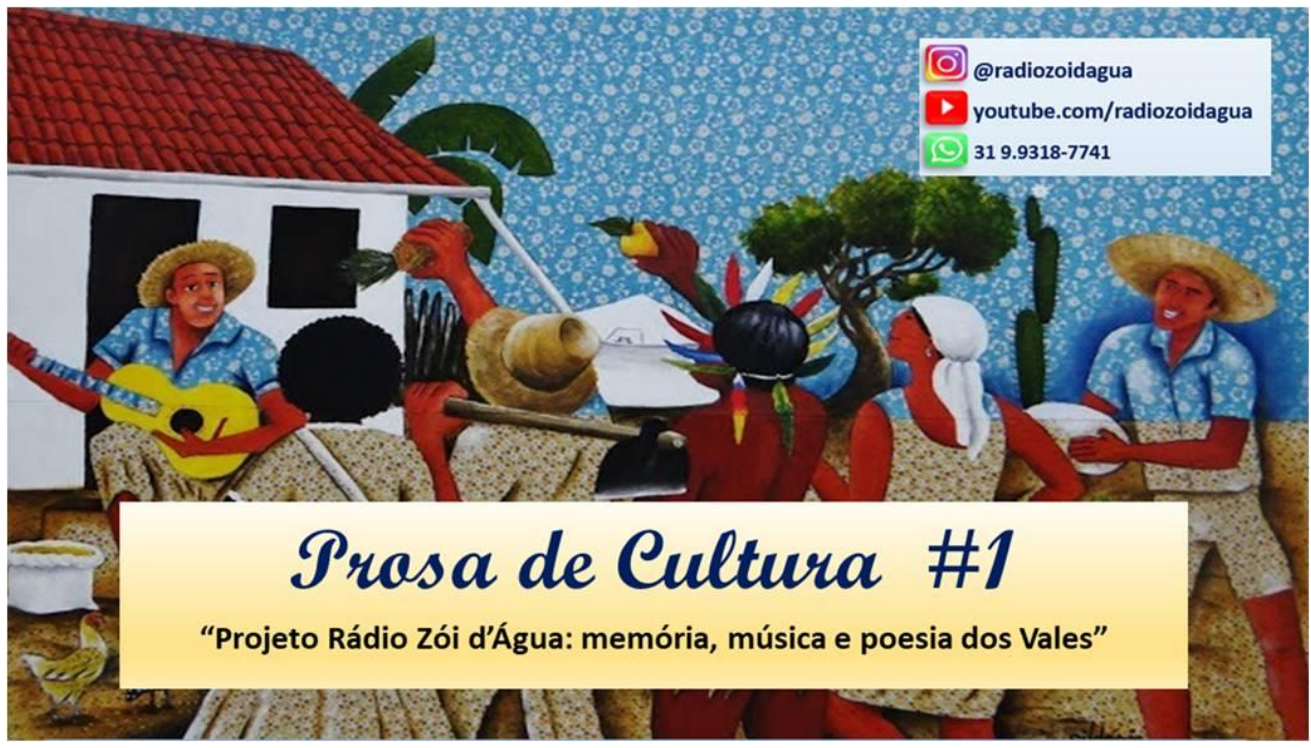

Fonte: Elaborada pela Equipe do Projeto. Imagem: Gildásio Jardim (2021).

Na primeira temporada do programa, houve grande variedade de atuação artística entre as pessoas convidadas:

- Bilora: compositor, violeiro e escritor;

- Gildásio Jardim: artista plástico e educador;

- Jandira Cangussu: arte-educadora e diretora de assuntos culturais;

- André Luiz Dias: ator, bailarino, dramaturgo, arte-educador e diretor; 


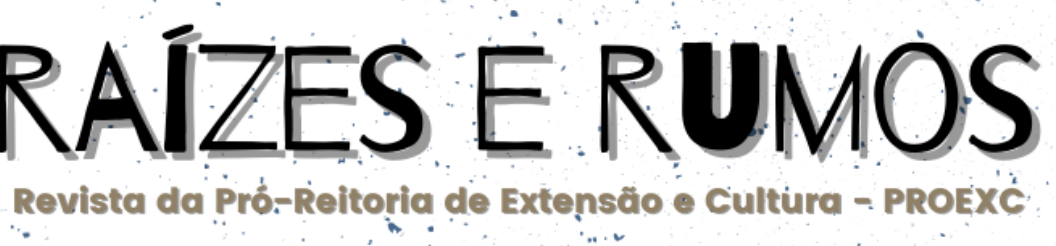

- Edileila Portes: artista plástica, professora e escritora;

- Beatriz Farias: compositora, cantora e produtora cultural.

A primeira temporada mostra que o programa, mesmo sendo de duração maior, mantém boa recepção por parte do público ouvinte. Isto se mostra pelas visualizações no canal do Youtube, que variam de 80 a 162, e também pelos comentários, que oscilam entre 10 a 20, superando, inclusive, a média de comentários do programa semanal "Prosa de Domingo", que é mais antigo.

Para a próxima temporada, o "Prosa de Cultura" manterá a periodicidade e a diversidade de áreas artísticas das pessoas convidadas, incluindo escritores(as). A ideia é fortalecer esse espaço de divulgação da produção artística das regiões do Mucuri e do Jequitinhonha, além de promover a difusão da crítica sobre a cultura.

\section{Prosa Literária}

A receptividade e retorno dos(as) artistas e público do quadro "Hora de Poesia", do programa "Prosa de Domingo", foi a inspiração para a criação do terceiro programa do projeto Rádio Zói d'Água: o "Prosa Literária". O desejo surgiu na chegada de novos voluntários ligados à literatura em fevereiro de 2021. Desde o início, a ideia foi a criação de uma série de pequenos episódios, apresentando fatos de destaque ou projetos atuais de escritores do cenário regional.

Para Antônio Cândido (1984), a importância da literatura deve ser reconhecida a partir do momento em que os direitos que asseguram a integridade espiritual dos seres humanos, como a crença, a opinião, a arte e a literatura também devem ser consideradas fundamentais. O autor marca ainda a literatura como um espaço de questionamento e busca de direitos. Esses princípios caminham junto com a consciência crítica defendida por Paulo Freire (2007), onde a aprendizagem se dá em diferentes espaços, num processo democrático e colaborativo.

Após um longo período de discussão, para delineamento do formato do "Prosa Literária", o programa foi ao ar pela primeira vez no dia 22 de junho de 2021, no canal do YouTube. 
A escolha das apresentadoras foi um contraponto para as vozes majoritariamente masculinas nos programas antecedentes. Em linhas gerais, após um primeiro esboço realizado em equipe, as pesquisas, textos, entrevistas e apresentações são realizadas por duas voluntárias e uma discente extensionista. A edição final é realizada pelo coordenador.

Para a primeira temporada optou-se por uma série semanal, com 14 programas de 10 a 15 minutos, publicados sempre às terças-feiras, por volta das 18 horas. Intercalando escritores dos Vales do Mucuri e Jequitinhonha, o programa se propõe também a apresentar obras e projetos ligados à literatura da região. Até o momento foram produzidos seis programas, sendo um episódio inicial de apresentação do projeto, duas entrevistas com escritoras do Vale do Mucuri (Lívia Ferreira e Ísis Caldeira), duas entrevistas com poetas do Vale do Jequitinhonha (Maguidá Freitas e Diêgo Alves) e um programa de apresentação do Movimento dos Poetas e Escritores do Vale do Jequitinhonha.

A equipe planejou em conjunto o layout modelo do cartaz de divulgação. Foi feita a opção por um layout simples, que valorizasse a delicadeza da imagem e trouxesse elementos que remetessem às artes dos projetos anteriores, como pode ser visto na Figura 3.

Figura 3: Capa do Programa "Prosa Literária" - edição de 20/07/2021.

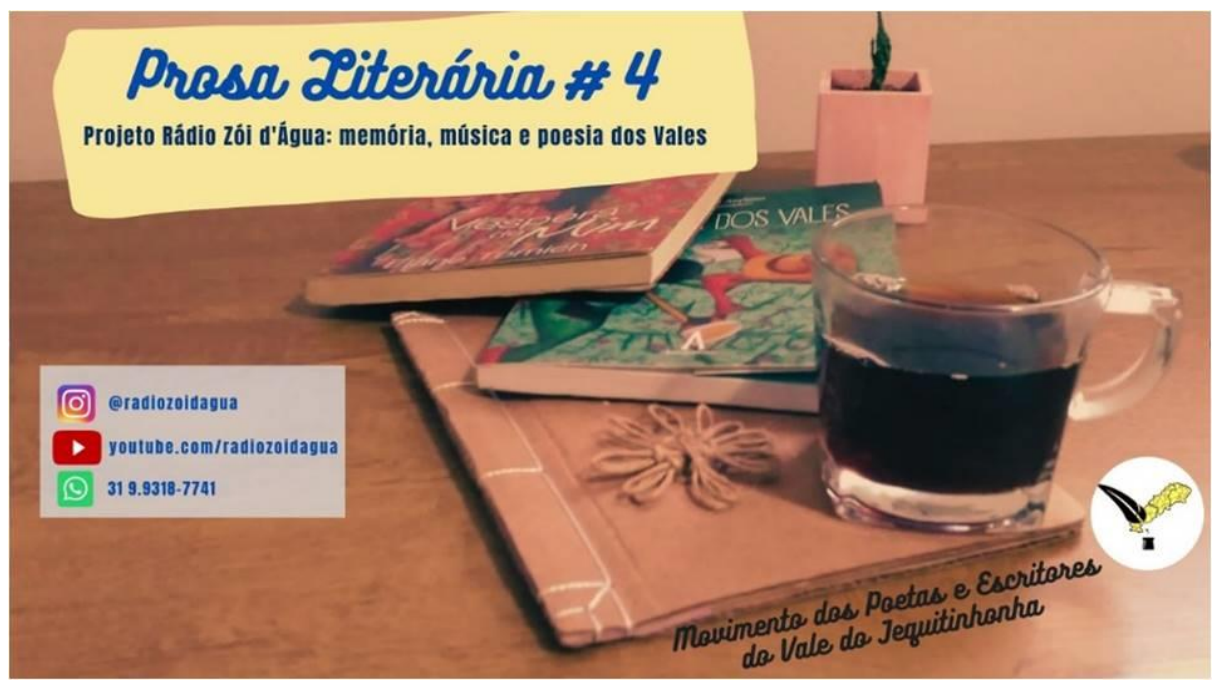

Fonte: Elaborada pela Equipe do Projeto. Foto de componente (2021).

Raízes e Rumos, Rio de Janeiro, v.9 n.2, p. 92-103, jul.-dez., 2021 


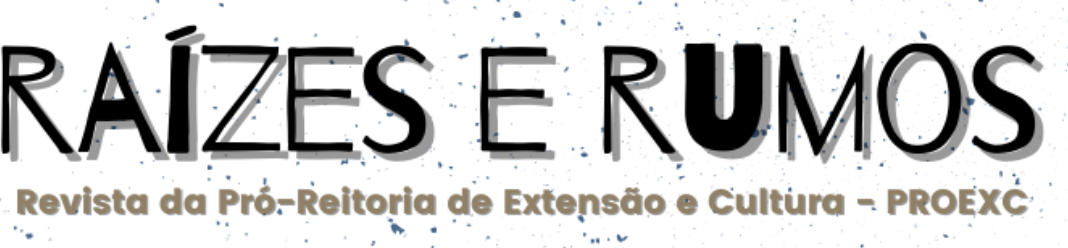

ISSN: $2317-7705$ online

O programa traz consigo uma série de contribuições, que sobrepujam a simples divulgação de artistas: o diálogo entre gerações, entre escritores consagrados e iniciantes, entre publicados e não publicados, o cuidado com a representatividade, o trabalho em equipe, o apreço com a biografia dos participantes, as parcerias com outros programas e projetos, a valorização da literatura regional.

Possivelmente, essa mosaico de caminhos de reconhecimento e valorização literária seja o responsável pelo importante retorno que o projeto tem recebido, seja pelos escritores participantes, seja pelos ouvintes do "Prosa Literária". "Projetos como esse são fundamentais para mostrar as florescências poéticas de nossos Vales" e "Maravilhosa conversa. Como é bom sentir dentro do peito o despertar para novos caminhos, vocês são inspirações profundas, os vales são presenças vivas em nosso cotidiano. Muito grata! Parabéns mulheres que nos encorajam" são dois dos tantos comentários deixados nas redes sociais do projeto. Já foram alcançadas mais de 500 visualizações e mais de 70 comentários.

Para a continuidade do projeto, a ideia é finalizarmos a primeira temporada e realizar uma avaliação dos pontos positivos e negativos da execução do "Prosa Literária", para planejamento da temporada seguinte. Serão apresentados ainda a Academia de Letras de Teófilo Otoni, o projeto Versinhos de Bem-Querer e a obra Tertúlia dos Vales, além de outros quatro escritores dos Vales. Foi frisada também a importância de se investir na divulgação em redes sociais diversas, com peças virtuais atrativas e frequentes.

\section{Considerações finais}

A produção dos programas deste projeto de extensão caminha sobre as ideias de Fernandes (2013) acerca das mídias alternativas. Diferente das mídias tradicionais, as alternativas apresentam-se a partir da busca da comunicação como um bem comum, num movimento contra-hegemônico. O maior acesso à internet tem sido um facilitador das mídias alternativas, contribuindo com a democratização da informação. Dessa maneira, vale ressaltar que os conteúdos produzidos não atingem apenas a 


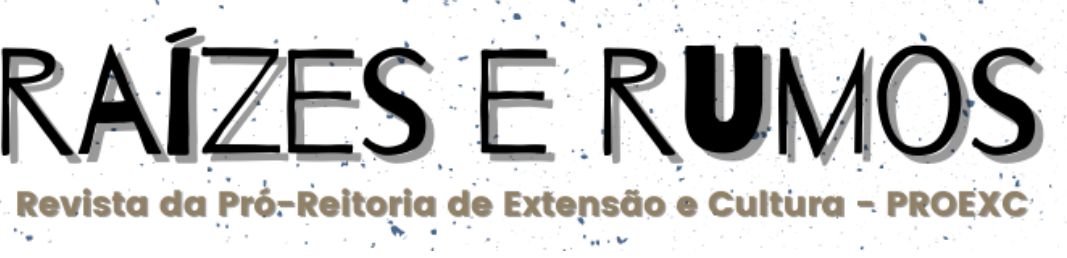

- ISSN: $2317-7705$ online

comunidade escolar, pois estão disponíveis para toda a comunidade com acesso à rede de internet.

É possível notar como o “Projeto 'Rádio Zói d’Água': memória, música e poesia dos Vales" não só evoluiu como projeto vinculado à Universidade, mas ultrapassou os limites do ambiente acadêmico, conectando-se num nível mais profundo com os Vales. Essa conexão se dá não só porque ele se propõe a valorizar a cultura regional e popular, mas também se coloca como um espaço de divulgação do trabalho de artistas que não costumam receber reconhecimento nos meios de comunicação tradicionais.

O projeto é, portanto, um exemplo da importância da extensão universitária, uma parte necessária no tripé "ensino, pesquisa e extensão" para a formação integral dos cidadãos, que não se limita à sala de aula. Além disso, demonstra a necessidade da afirmação e defesa do direito à educação pública e gratuita, contra os seus cada vez mais constantes ataques. Para Sousa (2000, p.207) “está nas mãos da Extensão Universitária fazer com que a própria Universidade seja relevante socialmente". E isso se coloca por meio de uma práxis que permite não só que a sociedade e a academia se influenciem, mas que elas sejam intrínsecas e essenciais uma outra.

O Projeto de Extensão "Rádio Zói d'Água" contribui no processo de socialização da Universidade, e trabalha no resgate e divulgação da cultura regional, por meio de seus canais no YouTube e no Instagram. Mais do que isso, busca despertar o sentimento de pertencimento da população e da UFVJM e, num sentido mais amplo, o caráter emancipatório e revolucionário da cultura popular.

\section{Referências}

BRASIL. Constituição (1988). Constituição da República Federativa do Brasil. Brasília, DF: Centro Gráfico, 1988.

CANDIDO, Antônio. "O direito à literatura”. In: Vários escritos. São Paulo: Duas cidades; Ouro sobre azul, 1995, p. 169-91.

FERNANDES, Vivian de Oliveira Neves. "Panorama da mídia alternativa no Brasil e na América Latina". $9^{\circ}$ Encontro Nacional de História da Mídia. Ouro Preto-MG, 
2013. Disponível em: http://www.ufrgs.br/alcar/encontros-nacionais-1/9oencontro-2013/artigos/gt-historia-da-midia-alternativa/panorama-da-midiaalternativa-no-brasil-e-na-america-latina Acesso em 22 jul. 2021.

FREIRE, Paulo. Educação como prática da liberdade. $30^{a}$ ed. São Paulo: Paz e Terra, 2007.

SOUSA, Ana Luiza Lima. A história da extensão universitária. Campinas: Ed. Alínea, 2000.

UFVJM. Assessoria de Assuntos Estratégicos e Institucionais. Portal UFVJM.

Disponível em: http://portal.ufvim.edu.br/page/aaei. Acesso: 06 de agosto de 2021. 